\title{
EFEITOS DA CALAGEM E DA ADUBAÇÃO FOSFATADA NA PRODUÇÃO DE MUDAS DE GOIABEIRA
}

\author{
William Natale ${ }^{1}$ \\ José Frederico Centurion' \\ Fábio Patto Kanegae ${ }^{2}$ \\ Flávia Consolini ${ }^{3}$ \\ Itamar Andrioli ${ }^{1}$
}

\section{RESUMO}

O ensaio teve por fim estudar os efeitos da calagem e da aplicação de fósforo no desenvolvimento de mudas de goiabeira. Usou-se um fatorial de 4 x 4, em três blocos casualizados. Foram empregadas doses crescentes de calcário e de adubo fosfatado, observando-se seus reflexos no solo, na produção de matéria seca e em parâmetros biológicos do desenvolvimento das plantas. Pelos resultados, verificou-se que a calagem e a adubação fosfatada elevaram os valores de $\mathrm{Ca}, \mathrm{Mg}, \mathrm{SB}, \mathrm{V}$ e $\mathrm{pH}$ do solo, ocorrendo o inverso com $\mathrm{H}+\mathrm{Al}$. Nas plantas, a aplicação provocou elevação dos teores de $\mathrm{Mg}$ e $\mathrm{P}$ e diminuição de $\mathrm{Mn}$ e $\mathrm{Zn}$. De maneira geral, as doses de calcário $\left(1,2 \mathrm{~g} \mathrm{dm}^{-3}\right)$ e de fósforo $\left(200 \mathrm{mg} \mathrm{dm}^{-3}\right)$, foram suficientes para atingir os maiores pesos de matéria seca das mudas de goiabeira.

Palavras-chave: Psidium guajava, fruta, goiaba, calagem, fósfóro.

1 Professor Adjunto, Departamento de Solos e Adubos, FCAV/UNESP, Câmpus de Jaboticabal. CEP 14870-000, Jaboticabal, SP, Brasil. E-mail: Natale@fcav.unesp.br

2 Ex-estagiário do Departamento de Solos e Adubos, FCAV/UNESP, Câmpus de Jaboticabal.

3 Pós-graduanda do Departamento de Solos e Adubos, FCAV/UNESP, Câmpus de Jaboticabal. 


\section{ABSTRACT}

\section{EFFECTS OF PHOSPHATE FERTILIZATION AND LIMING ON THE INITIAL DEVELOPMENT OF GUAVA PLANTS}

The effect of phosphate fertilization and liming on the initial development of guava plant (Psidium guajava) was studied. The treatments consisted of four phosphorus levels and four liming levels, in three randomized complete blocks. Samplings for soil and plant analyses were carried out. The liming of soil and application of $P$ fertilizer affected in an increasing way the amounts of $\mathrm{Ca}, \mathrm{Mg}$ and $\mathrm{P}$ in the soil, the same happening with $\mathrm{pH}$ values, $\mathrm{V}$ and the inverse with $\mathrm{H}+\mathrm{Al}$. The use of increasing doses of limestone and $\mathrm{P}$ fertilizer promoted an increment in the amounts of $\mathrm{Mg}$ and $\mathrm{P}$ on the plants and caused a decrease of $\mathrm{Mn}$ and $\mathrm{Zn}$ content. It was found that the lower levels of liming and $\mathrm{P}$ fertilization showed the best results for dry matter production.

Key words: Psidium guajava, fruit, guava, liming, phosphorus.

\section{INTRODUÇÃO}

A utilização de mudas sadias e vigorosas é um dos fatores que determina o sucesso da implantação de um pomar. A produção de plantas com alta qualidade em período curto de tempo é, pois, uma imposição da fruticultura moderna. No caso da goiabeira, o desenvolvimento de plantas a partir de estacas herbáceas, tem sido o caminho mais indicado para a obtenção de pomares homogêneos, utilizando-se cultivares que possuem alto potencial genético de produção.

Foram realizados vários estudos sobre aspectos ligados à nutrição, adubação e desenvolvimento de goiabeiras, a partir do plantio definitivo da muda no campo (Natale, 1993; Natale, 1999). Porém, inexistem informações nesse sentido quando se trata da produção de mudas em viveiros ou estufas. 
O sucesso de um viveiro de mudas está estreitamente ligado à escolha do substrato de enraizamento. Nele, os elementos nutritivos devem estar presentes sob forma prontamente assimilável pela planta e em quantidades suficientes para satisfazer suas necessidades, mas sem excess ) (Aubert \& Vullin, 1997). Devido ao rápido crescimento das plantas, às pequenas dimensões dos recipientes para o desenvolvimento das raízes, as altas taxas de lixiviação, além do uso de subsolo (praticamente inerte) como substrato, o ambiente radicular é um dos aspectos que merece rigorosa atenção.

Uma melhor fertilidade do solo a ser utilizado como substrato para produção de mudas implica, diretamente, em um maior desenvolvimento da planta. Entretanto, os solos mais férteis podem introduzir ervas daninhas e patógenos. Assim, por vezes, tem-se usado o subsolo como suporte para o crescimento inicial das plantas (Picheth, 1987).

Com o intuito de não degradar áreas extensas de solo e atender às exigências do Ministério da Agricultura para a produção de mudas certificadas (Brasil, 1970; Brasil, 1977), as quais devem estar livres de ervas daninhas (especialmente tiririca), os viveiristas têm utilizado como substrato, todo o perfil de solo disponível (0 - $4 \mathrm{~m}$ de profundidade).

As implicações do uso do subsolo como substrato para produção de mudas, sem a devida correção das condições adversas ao crescimento das plantas, têm causado sérios problemas, principalmente em relação ao pegamento. Dentre os fatores ambientais do solo, os ligados à acidez são os que mais interferem no desenvolvimento das plantas, especialmente nas regiões tropicais (Sanchez \& Salinas, 1983).

Além da acidez, os solos e subsolos das regiões tropicais apresentam normalmente pequena disponibilidade de fósforo (Lopes, 1984; Raij, 1991), elemento fundamental no desenvolvimento de raizes (Marschner, 1995) e, conseqüentemente das plantas. Embora não seja um elemento muito exportado pelos frutos da goiabeira durante as colheitas (Natale, 1993), a carência de fósforo no solo impede o rápido estabelecimento do pomar. 
Com base no exposto e considerando a inexistência de informações sobre o assunto, procurou-se determinar a influência da aplicação do corretivo da acidez e do adubo fosfatado no desenvolvimento de mudas de goiabeira. Para tanto foram utilizadas doses crescentes de um calcário dolomítico e de termofosfato magnesiano, observando-se seus reflexos no solo, nas plantas e em alguns aspectos biológicos do seu desenvolvimento.

\section{MATERIAL E MÉTODOS}

O experimento foi desenvolvido em um viveiro comercial de mudas, localizado à Rodovia Washington Luiz, km 333,8 no município de Taquaritinga, SP.

Foram utilizadas plantas obtidas a partir de propagação vegetativa de estacas herbáceas de matrizes selecionadas de goiabeiras (Psidium guajava L.) cv. Paluma.

Após o enraizamento inicial, as estacas foram transferidas para sacos plásticos com $3 \mathrm{~kg}$ de substrato, este era constituído da mistura de um Argissolo Vermelho-Amarelo em todo o perfil ( 0 - $4 \mathrm{~m})$, proveniente do próprio viveiro comercial. $A$ análise química inicial para fins de fertilidade, encontra-se na Tabela 1.

Tabela 1. Análise química para fins de fertilidade do Argissolo Vermelho-Amarelo (substrato) utilizado para a produção de mudas de goiabeira

\begin{tabular}{|c|c|c|c|c|c|c|c|c|c|}
\hline $\begin{array}{c}\mathrm{pH} \\
\mathrm{CaCl}_{2}(0,01 \mathrm{M})\end{array}$ & M.O. & $\begin{array}{c}P \\
\text { (resina) }\end{array}$ & $K$ & $\mathrm{Ca}$ & $\mathrm{Mg}$ & $\mathrm{H}+\mathrm{Al}$ & SB & $T$ & v \\
\hline & $\mathrm{g} \mathrm{kg}^{-1}$ & $\mathrm{mg} \mathrm{dm}^{-3}$ & $-\cdots$ & 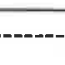 & $\mathrm{mmc}$ & $\mathrm{dm}^{-3} \ldots$ & 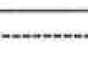 & 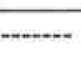 & \\
\hline 4,4 & 5 & 1 & 1,1 & 6 & 3 & 2,8 & 10,1 & 38,1 & $27 \%$ \\
\hline
\end{tabular}


Usou-se um fatorial de $4 \times 4$ (quatro doses de corretivo $\times$ quatro de fósforo), em três blocos casualizados. Cada parcela experimental tinha três plantas, perfazendo 144 mudas de goiabeira no total.

As doses de calcário foram calculadas considerando-se a saturação por bases ideal para a cultura (Santos \& Quaggio, 1996), igual a 70\%, como segue:

- $\mathrm{C}_{0}=$ zero de calcário;

- $\mathrm{C}_{1}=$ a dose calculada para elevar $\mathrm{V}=70 \%(1,2 \mathrm{~g}$ de calcário por $\mathrm{kg}$ de substrato);

- $\mathrm{C}_{2}=1,5$ vez a dose indicada para elevar $\mathrm{V}=70 \%$ (1,8 g de calcário por $\mathrm{kg}$ de substrato);

- $\mathrm{C}_{3}=2$ vezes a dose calculada para elevar $\mathrm{V}=70 \%(2,4 \mathrm{~g}$ de calcário por kg de substrato).

O calcário dolomítico empregado possuía $23,71 \%$ de $\mathrm{CaO}, 16,93 \%$ de $\mathrm{MgO}, \mathrm{RE}$ igual a $79,69 \%$, PN igual a $84,43 \%$ e PRNT de $67,28 \%$.

As diferentes doses do corretivo foram homogeneamente aplicadas ao solo, 90 dias antes do transplante das mudas e da aplicação do adubo fosfatado, a fim de reagir com tempo suficiente.

As doses de fósforo aplicado, no momento do transplante, foram calculadas conforme a recomendação geral de Malavolta (1980), que indica o uso de $200 \mathrm{ppm}$ de $\mathrm{P}\left(200 \mathrm{mg}\right.$ de $\mathrm{P} \mathrm{dm}^{-3}$ ou $458 \mathrm{mg}$ de $\mathrm{P}_{2} \mathrm{O}_{5} \mathrm{dm}^{-3}$ ), para ensaios em vaso, como segue:

- $\mathrm{P}_{0}=$ zero de fósforo;

- $\mathrm{P}_{1}=$ metade da dose recomendada $=100 \mathrm{mg} \mathrm{de} \mathrm{P} \mathrm{dm}^{-3}$ ou $229 \mathrm{mg} \mathrm{P}_{2} \mathrm{O}_{5} \mathrm{dm}^{-3}$;

- $\mathrm{P}_{2}=$ a dose recomendada $=200 \mathrm{mg}$ de $\mathrm{P} \mathrm{dm} \mathrm{dm}^{-3}$ ou $458 \mathrm{mg} \mathrm{P}_{2} \mathrm{O}_{5} \mathrm{dm}^{-3}$;

- $\mathrm{P}_{3}=0$ dobro da dose recomendada $=400 \mathrm{mg} \mathrm{de} \mathrm{P} \mathrm{dm}^{-3}$ ou $916 \mathrm{mg} \mathrm{P}_{2} \mathrm{O}_{5} \mathrm{dm}^{-3}$. 
O termofosfato magnesiano utilizado possuía as seguintes características: $18 \%$ de $\mathrm{P}_{2} \mathrm{O}_{5}$ total; $16,5 \%$ de $\mathrm{P}_{2} \mathrm{O}_{5}$ solúvel em ácido cítrico $2 \%$; $14,5 \%$ de $\mathrm{MgO} ; 28 \%$ de $\mathrm{CaO} ; 75 \%$ do produto passando em peneira $\mathrm{n}^{\circ}$ 100 ABNT.

Os tratos culturais (irrigação, controle de ervas daninhas, pragas e doenças), no período de condução do ensaio, foram os normalmente utilizados pelo viveirista. A adubação $\mathrm{N}$ e $\mathrm{K}$ foi constante em todas as parcelas.

As avaliações dos efeitos dos tratamentos foram realizadas no momento em que as mudas estavam suficientemente desenvolvidas para ir ao campo, ou seja, 90 dias após o transplante. Cortaram-se as mudas rente ao solo, separando a parte aérea das raízes, analisando-se quimicamente o tecido vegetal conforme recomendação de Bataglia et al. (1983). Após a retirada das plantas, o substrato dos sacos plásticos foi seco e analisado de acordo com a metodologia descrita por Raij et al. (1987).

\section{RESULTADOS E DISCUSSÃO}

Os resultados das análises químicas para fins de fertilidade, do substrato utilizado no ensaio de produção de mudas de goiabeira, revelaram que os únicos parâmetros não afetados pelos tratamentos foram os teores de potássio trocável e os de matéria orgânica. Os teores de $\mathrm{K}$ estiveram sempre dentro da faixa considerada alta (Raij et al., 1996), uma vez que todas as parcelas receberam o elemento a fim de que não fosse limitante ao desenvolvimento das plantas. O conteúdo de matéria orgânica, por sua vez, revelou-se baixo, como esperado, tendo em vista que foi utilizado todo o perfil disponível do um Argissolo Vermelho-Amarelo.

Tanto o corretivo quanto o fertilizante afetaram de modo significativo e positivo os teores de cálcio e magnésio e, ainda, os valores da soma de bases, a capacidade de troca catiônica, a saturação por bases, o $\mathrm{pH}$ do solo e, de modo inverso, a acidez potencial. Isto é consequiência da composição do calcário dolomítico empregado, que tem carbonatos de cálcio e de magnésio em sua constituição, contribuindo para a elevação 
dos teores de Ca e $\mathrm{Mg}$, com conseqüente elevação de $\mathrm{SB}, \mathrm{V}, \mathrm{pH}$ e diminuição de $\mathrm{H}+\mathrm{Al}$. A liberação de cargas negativas dependentes do $\mathrm{pH}$ explica o aumento dos valores da CTC do solo, promovendo maior retenção de cátions trocáveis (Defelipo \& Braga, 1983).

Explicação semelhante pode ser dada para os efeitos do termofosfato magnesiano utilizado no ensaio, o qual possui em sua composição silicatos de cálcio e magnésio, além de fornecer fósforo.

$\mathrm{Na}$ Tabela 2 é apresentada a análise de variância para os teores de fósforo no solo, produção de matéria seca da parte aérea, das raízes, parte aérea + raízes e do comprimento das mudas de goiabeira. Verifica-se na Figura 1 que com o incremento nas doses do fertilizante fosfatado ocorreu aumento no teor de $\mathrm{P}$ disponível no solo. Observa-se ainda, que, nas doses mais baixas de adubo, o aumento nos teores determinados pela análise de solo não são tão expressivos quanto nas doses mais elevadas, nas quais os sítios de adsorção de $\mathrm{P}$, provavelmente já se encontrassem saturados, permitindo assim maior disponibilidade do elemento para as plantas. O estudo gráfico da superfície de resposta revelou, através das isolíneas, que o máximo absoluto atingiu $443 \mathrm{mg} \mathrm{de} \mathrm{P} \mathrm{dm}^{-3}$.

Por outro lado, independentemente da dose de corretivo aplicado, .ão houve alteração significativa do teor de $\mathrm{P}$ no tratamento sem fertilizante, isso devido aos teores originais de fósforo do solo (Tabela 1). Sezundo Raij et al. (1996), concentrações no solo abaixo de $5 \mathrm{mg}$ de $\mathrm{P} \mathrm{dm}^{-3}$ ;ão consideradas muito baixas. A dose $\mathrm{P}_{2}$ de fósforo, cerca de $200 \mathrm{ppm}$, ıdequada segundo Malavolta (1980), permitiu recuperar, nas análises relizadas, valores próximos àquele. Na ausência do calcário, porém, ou juando de seu uso na menor dose, esse valor cai praticamente à metade. sso se explica pelo fato de o corretivo atuar sobre as cargas dependentes lo $\mathrm{pH}$, diminuindo pois, os sítios que adsorvem o fósforo no solo.

De modo geral, o incremento nas doses de calcário promoveu maior cúmulo de magnésio na parte aérea, ocorrendo o inverso com o manganês o zinco. Isso está de acordo com Malavolta (1980), visto que a aplicaão do corretivo promoveu aumento da disponibilidade de magnésio no 


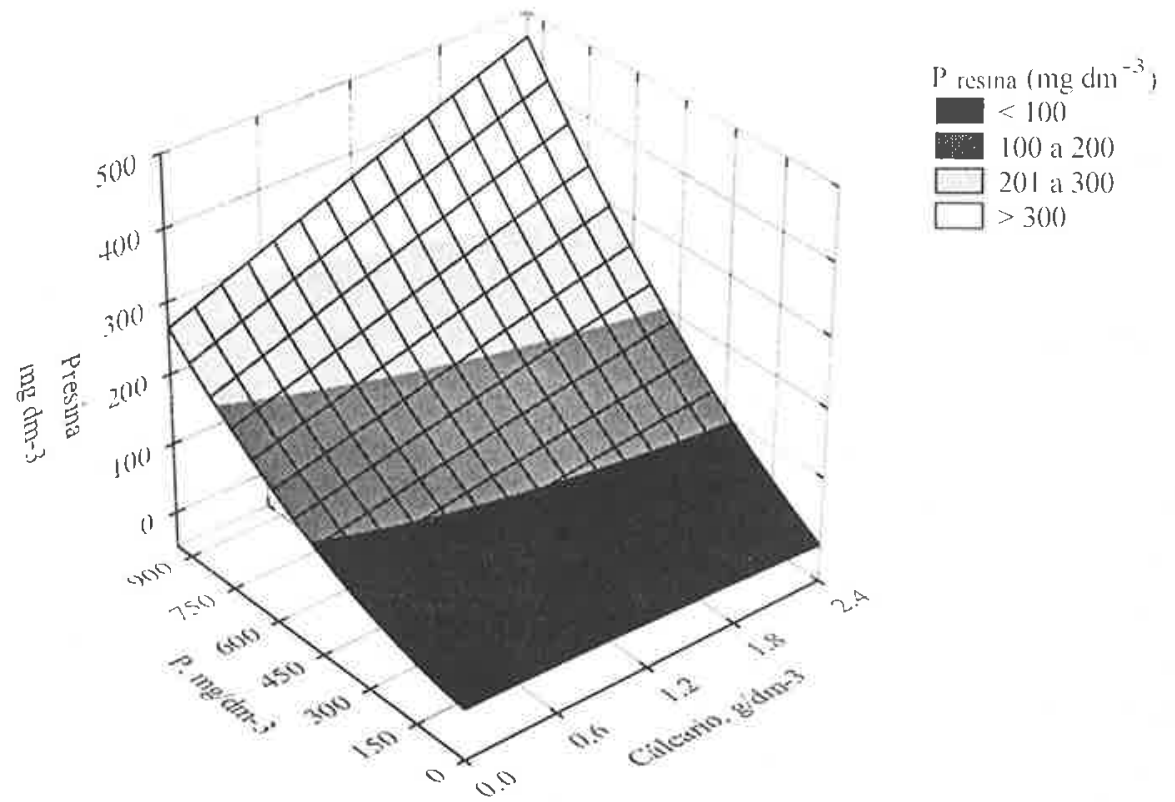

$P($ resina $)=21,03-4,12 \mathbf{C}+6,23 \cdot 10^{-2} \mathbf{P}-1,45 \mathbf{C}^{2}+2,04 \cdot 10^{-4} \mathbf{P}^{2}+9,01 \cdot 10^{-2} \mathbf{C P}, \mathbf{R}^{2}=0,98^{* *}$

Figura 1. Efeito de doses de calcário (C) e de adubo fosfatado (P) na concentração de fósforo em um Argissolo Vermelho-Amarelo utilizado para produção de mudas de goiabeira.

solo e, ainda, elevação do pH, com conseqüente diminuição da solubilidade de manganês e zinco no solo.

$\mathrm{O}$ incremento nas doses do fertilizante fosfatado provocou maior acúmulo de $\mathrm{P}$ na parte aérea das mudas de goiabeira, ocorrendo o inverso com o zinco. O aumento na concentração de P era esperado e, a diminuição da absorção de $\mathrm{Zn}$ também, devido às interações que ocorrem entre $\mathrm{P}$ e Zn. Observações semelhantes podem ser estendidas às raízes das plantas.

O número de pares de folhas não foi afetado por nenhum dos tratamentos, enquanto o comprimento das plantas apresentou menores valores na ausência do corretivo (Figura 2). 


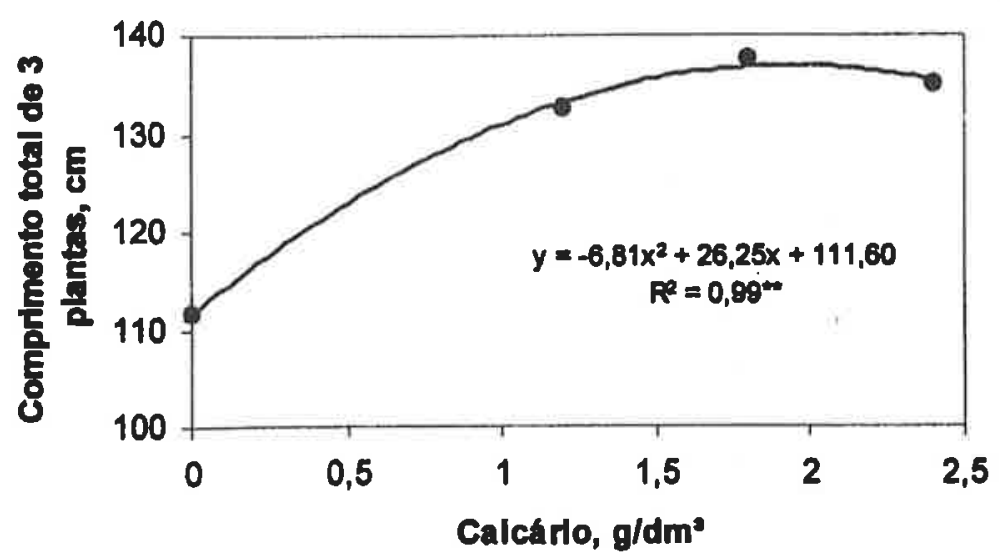

igura 2. Efeitos médios das doses de calcários no comprimento total das mudas de goiabeira (médias de 12 repetições).

O peso de matéria seca da parte aérea e, ainda, da parte aérea + dízes foram significativamente afetados pela aplicação do fertilizante ssfatado, conforme consta da Tabela 2. Apesar disso, os modelos estuados na análise de regressão não se ajustaram aos dados observados, onforme pode se verificar através da Tabela 3 . Verificou-se, porém, que $\mathrm{s}$ maiores pesos de matéria seca dessas características foram obtidas com menor dose de adubo fosfatado (100 $\mathrm{mg} \mathrm{de} \mathrm{P} \mathrm{dm}^{-3}$ ).

O desdobramento da interação significativa $(\mathrm{C} \times \mathrm{P})$ é mostrado na igura 3, na qual os maiores valores de peso de matéria seca de raízes ram alcançados com as menores doses de calcário e adubo fosfatado $z_{1} \times P_{1}$ ). O estudo gráfico da superfície de resposta revelou, através das olíneas, que o ponto de máximo esteve ao redor de $8,78 \mathrm{~g}$ e o de mínima 'óximo a 5,92 g de raízes (Figura 5).

Chama a atenção que os melhores resultados tenham sidơ obserıdos já com a primeira dose de adubo e de corretivo. Isso pode indicar, informe relatou Clarckson (1985), que plantas de origem tropical, como goiabeira, desenvolvidas geneticamente em solos de baixa disponibili- 


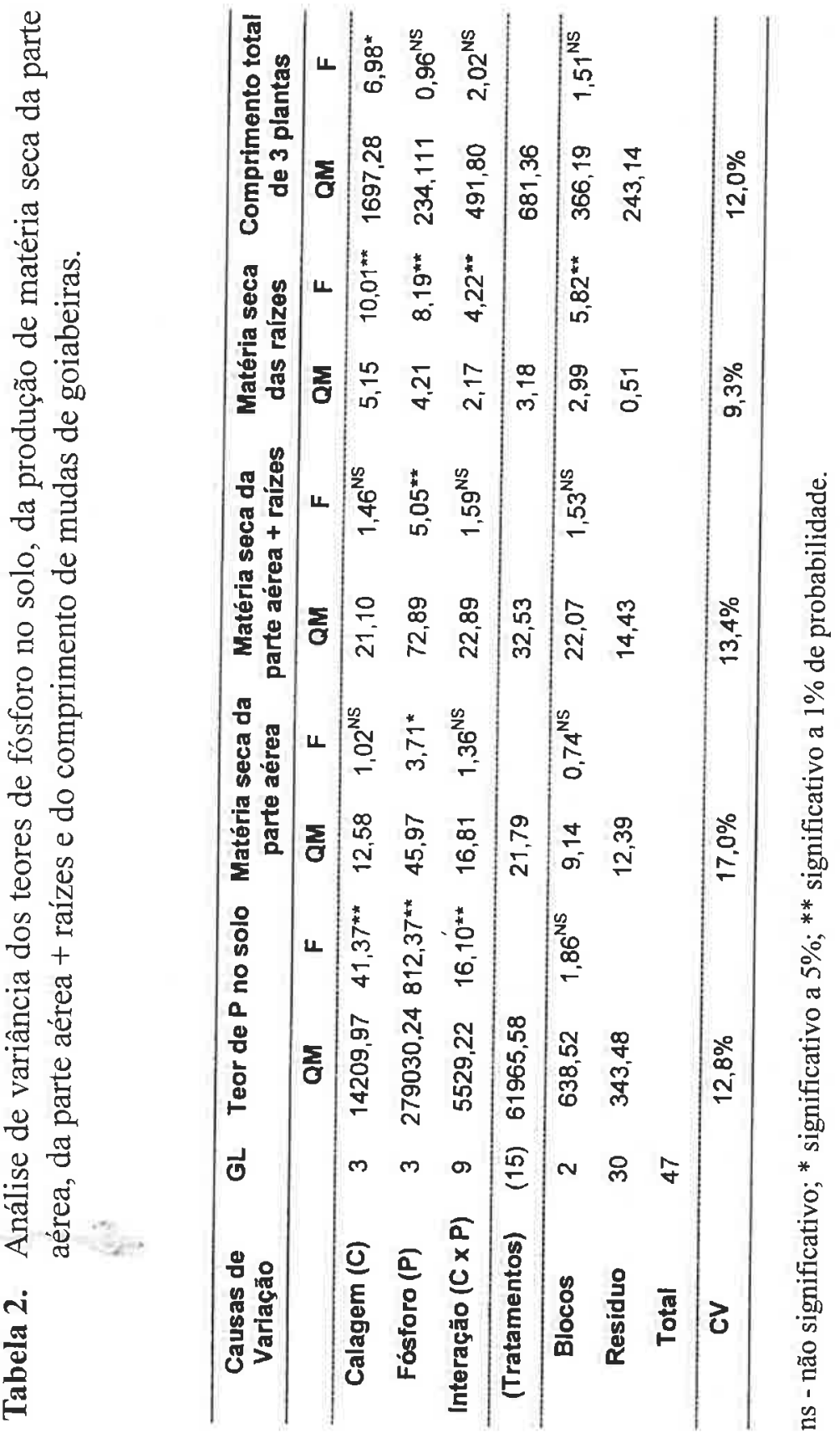




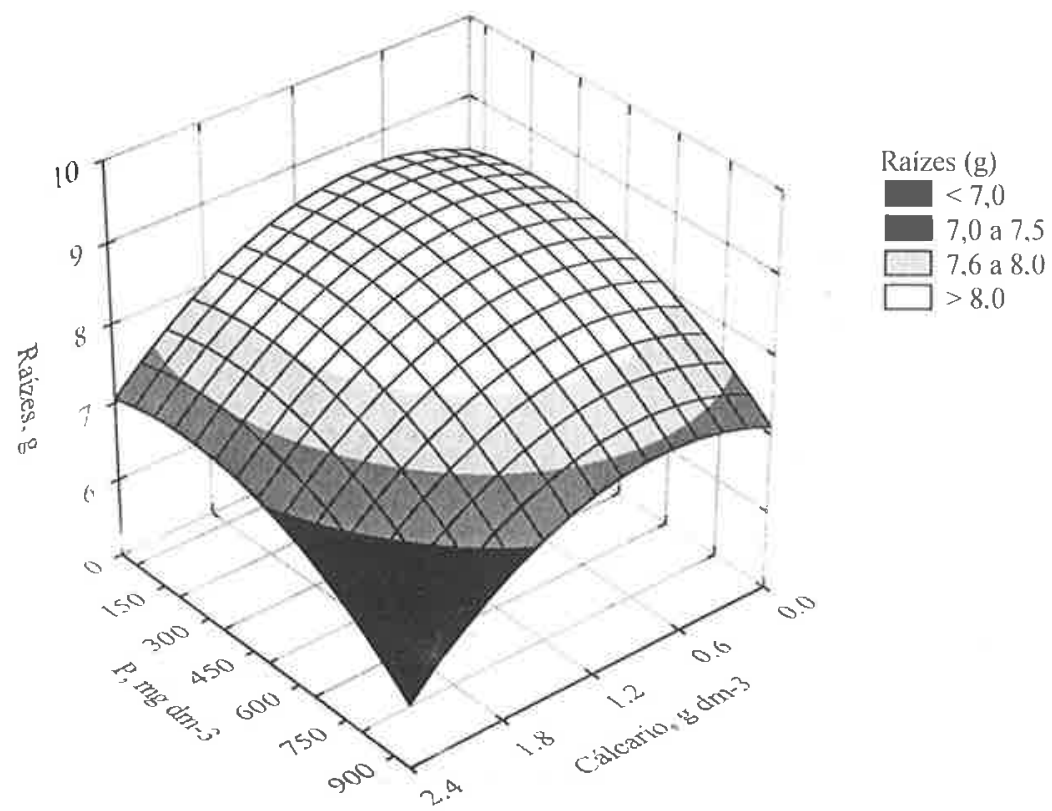

$\mathrm{MS}$ (raizes) $=8,30+8,87 \cdot 10^{-1} \mathbf{C}+1,27 \cdot 10^{-3} \mathbf{P}-5,86 \cdot 10^{-1} \mathbf{C}^{2}-2,67 \cdot 10^{-6} \mathbf{P}^{2}-2,04 \cdot 10^{-5} \mathbf{C P} \mathbf{R}^{2}=0,58^{*}$

Figura 3. Superfície de resposta relativa a MS(raízes) em função da dose de calcário $(\mathrm{C})$ e da dose de $\mathrm{P}$. O máximo $\mathrm{MS}$ (raízes) $=8,8 \mathrm{~g}$ ocorre para $\mathrm{C}=0,76 \mathrm{~g}$ de calcário $/ \mathrm{kg}$ de solo e $\mathrm{P}=238 \mathrm{mg}$ de $\mathrm{P} / \mathrm{dm}^{3}$.

dade de nutrientes, possuem alta capacidade de absorção e/ou elevada eficiência no uso de nutrientes, o que lhes conferiria baixa expectativa de resposta às aplicações de fertilizantes.

A literatura contém vários estudos sobre a influência da associação simbiótica entre goiabeiras e fungos micorrízicos-arbusculares (Schmidt \& Scow, 1986; Fischer et al. 1994; Kumaran \& Azizah, 1995; Srinivasan et al., 1996). Em pesquisas recentes, Chacón \& Cuenca (1998) e Samarão \& Martins (1999) concluíram que a goiabeira é muito dependente das micorrizas e que a adição de fertilizante fosfatado, na presença desses organismos, melhorou significativamente o desenvolvimento das 


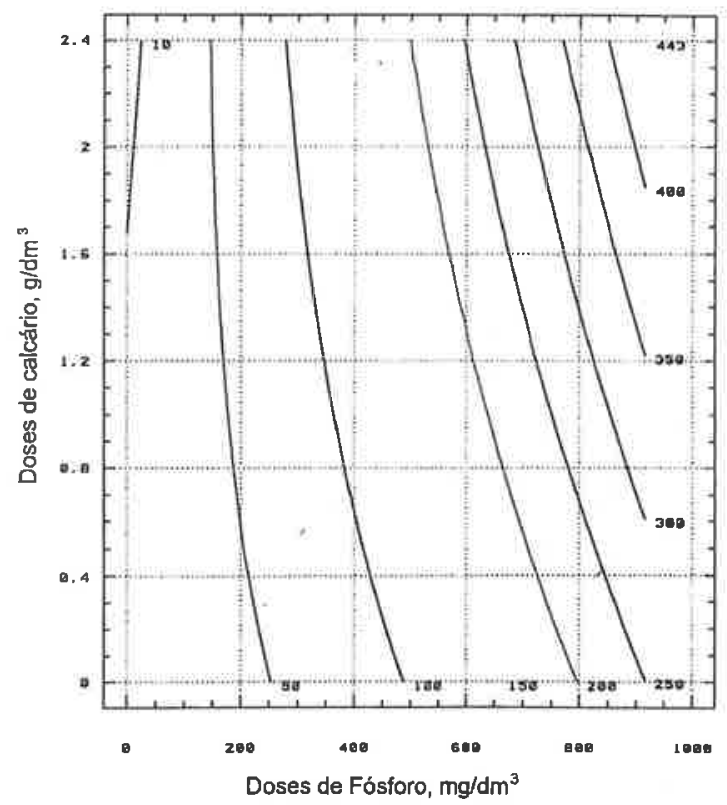

Figura 4. Isolineas da concentração de fósforo no Argissolo Vermelho-Amarelo em função das doses de calcário e de fósforo (ponto de máximo 443,0).

plantas. Esse é, pois, outro aspecto a ser considerado ao analisar os resultados do ensaio aqui descrito.

\section{CONCLUSÕES}

A aplicação de doses crescentes de calcáı io e adıbo fosfatado promoveu incremento nas concentrações de $\mathrm{Ca}, \mathrm{Mg}, \mathrm{P}, \mathrm{SB}, \mathrm{V}$ e no valor $\mathrm{pH}$ do solo, ocorrendo o inverso com a acidez potencial. Nas plantas a aplicação dos tratamentos provócou elevação dos teores de $\mathrm{Mg}$ e $\mathrm{P}$ e diminuição de $\mathrm{Mn}$ e $\mathrm{Zn}$. De maneira geral, as menores doses de calcário (1,2 g $\mathrm{dm}^{-3}$ ) e fósforo $\left(100 \mathrm{mg} \mathrm{dm}^{-3}\right)$, foram suficientes para atingir os maiores pesos de matéria seca das mudas de goiabeira. 


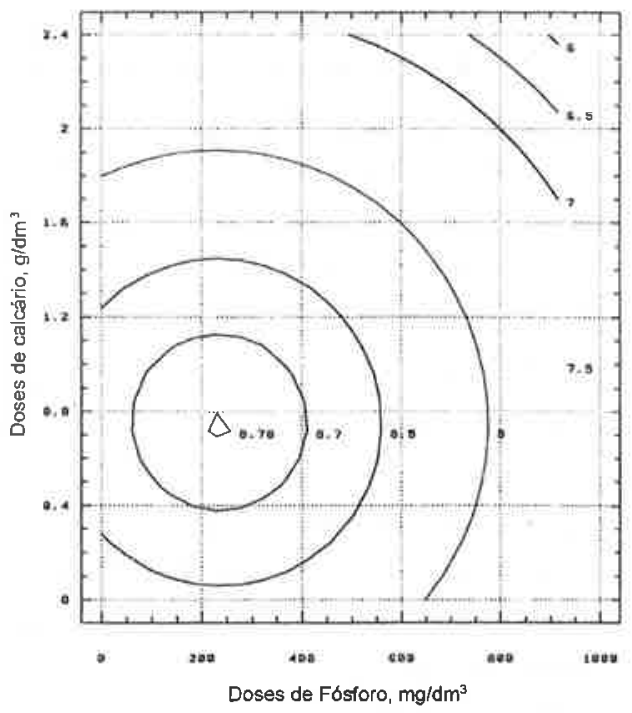

Figura 5. Isolineas dos pesos de matéria seca das raízes de mudas de goiabeiras em função das doses de calcário e de fósforo (ponto de máximo $8,8 \mathrm{~g}$, para $\mathrm{C}=0,76 \mathrm{~g}$ de calcário e $238 \mathrm{mg}$ de $\mathrm{P}$ por $\mathrm{kg}$ de solo).

\section{REFERÊNCIAS BIBIOGRÁFICAS}

AUBERT, B., VULlin, G. Pépinières et Plantations d'Agrumes. Montpellier, França, CIRAD/FLHOR, 1997. 184 p.

BATAGLIA, O.C. et al. Método de Análise Química de Plantas. Campinas: Instituto Agronômico, 1983. 48 p. (Boletim Técnico, 78).

BRASIL. Portaria ${ }^{0} 40$ de 20/05/1970 do Instituto Biológico. Diário Oficial, 22 de Mai. 1970. p. 59.

BRASIL. Portaria n 344 de 01/07/1977 do Ministério da Agricultura. CHACÓN, A.M., CUENCA, G. Efecto de las Micorrizas Arbusculares y de la Fertilización con Fósforo, Sobre el Crecimiento de la Guayaba en Condiciones de Vivero. Agronomía Tropical, 48(4): 425-440, 1998. 
CLARKSON, D.T. Factors Affecting Mineral Nutrient Acquisition by

Plants. Annual Review of Plant Physiology, 36: 77-115, 1985.

DEFELIPO, B. V., BRAGA, J.M. . Influência da Calagem e Fontes de

Potássio na Adsorção de Potássio em Latossolos em Minas Gerais.

R. bras. ci. solo, 7: 119-122, 1983.

FISCHER, C.R. et al. Mycorrhiza Inoculum Potentials in Tropical

Secondary Succession. Biotropica, 26(4): 369-377, 1994.

KUMARAN, S., AZIZAH, H.C. Influence of Biological Soil Conditioner

on Mycorrhizal Versus Non-Mycorrhizal Guava Seedlings. Tropical Agriculture, 72(1): 39-43, 1995.

LOPES, A. S. Solos sob "Cerrado": Características, Propriedades e Manejo. 2. ed. Piracicaba: POTAFOS, 1984. 162 p.

MALAVOLTA, E. Elementos da Nutrição Mineral de Plantas. São

Paulo: Ceres, 1980.251 p.

MARSCHNER, H. Mineral Nutrition of Higher Plants. London: Academic Press, 1995. 674 p.

NATALE, W. Diagnose da Nutrição Nitrogenada e Potássica em Duas Cultivares de Goiabeira (Psidium guajava L.), Durante Três Anos. Piracicaba, 1993. 149 p. Tese (Doutorado em Agronomia - Área de Concentração em Solos e Nutrição de Plantas) - ESALQ/USP.

NATALE, W. Resposta da Goiabeira à Adubação Fosfatada. Jaboticabal, 1999. 132 p. Tese (Livre-Docência) FCAV/UNESP, Câmpus de Jaboticabal.

PICHETH, J. A. T. F. . Viveiros Florestais. Londrina: 1987. 29 p. (Circular, 52).

RAIJ, B. van. Fertilidade do Solo e Adubação. Piracicaba, POTAFOS, $1991.343 \mathrm{p}$.

RAIJ, B. van et al. (Ed.) Recomendações de Adubação e Calagem para o Estado de São Paulo. Campinas: Instituto Agronômico do Estado de São Paulo, 1996. 285p.

RAIJ, B. van et al. Análise Química do Solo Para Fins de Fertilidade. Campinas: Fundação Cargill, 1987. 170 p. 
SAMARÃO, S.S., MARTINS, M.A. Influência de Fungos Micorrízicos Arbusculares, Associada à Aplicação de Rutina, no Crescimento de Mudas de Goiabeira (Psidium guajava L.). R. Bras. Fruticultura, 21(2): 196-199, 1999.

SANCHEZ, P.A., SALINAS, J.G. Suelos Acidos. Bogotá: SCCS, 1983. $93 \mathrm{p}$.

SANTOS, R.R., QUAGGIO, J.A. Gioaba. In: RAIJ, B. van et al. (Ed.) Recomendações de Adubação e Calagem para o Estado de São Paulo. Campinas: Instituto Agronômico do Estado de São Paulo, 1996. p. 143.

SCHMIDT, S.K., SCOW, K.M. Mycorrhizal Fungi on the Galápagos Islands. Biotrópica, 18(3): 236-240, 1986.

SRINIVASAN, D., Influence of effluent irrigation on VA Mycorrhizae.

Indian Journal of Microbiology, 36(3): 37-40, 1996. 